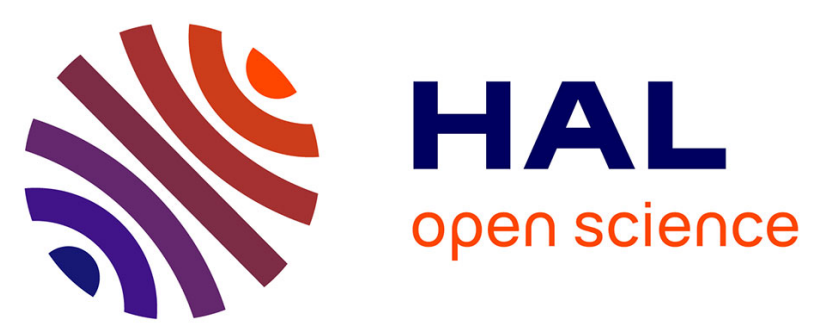

\title{
Porphyromonas spp. have an extensive host range in ill and healthy individuals and an unexpected environmental distribution: A systematic review and meta-analysis
}

\author{
Luis Acuña-Amador, Frédérique Barloy-Hubler
}

\section{To cite this version:}

Luis Acuña-Amador, Frédérique Barloy-Hubler. Porphyromonas spp. have an extensive host range in ill and healthy individuals and an unexpected environmental distribution: A systematic review and meta-analysis. Anaerobe, 2020, 66, pp.102280. 10.1016/j.anaerobe.2020.102280 . hal-02974793

\section{HAL Id: hal-02974793 \\ https://hal.science/hal-02974793}

Submitted on 16 Nov 2020

HAL is a multi-disciplinary open access archive for the deposit and dissemination of scientific research documents, whether they are published or not. The documents may come from teaching and research institutions in France or abroad, or from public or private research centers.
L'archive ouverte pluridisciplinaire HAL, est destinée au dépôt et à la diffusion de documents scientifiques de niveau recherche, publiés ou non, émanant des établissements d'enseignement et de recherche français ou étrangers, des laboratoires publics ou privés. 
1 Porphyromonas spp. have an extensive host range in ill and healthy individuals and an 2 unexpected environmental distribution: a systematic review and meta-analysis.

3

4 Luis Acuña-Amador ${ }^{\mathrm{a},}{ }^{*}$ and Frédérique Barloy-Hubler ${ }^{\mathrm{b}}$

5

6 a Laboratorio de Investigación en Bacteriología Anaerobia, Centro de Investigación en 7 Enfermedades Tropicales, Facultad de Microbiología, Universidad de Costa Rica, San José, 8 Costa Rica

9 bInstitut de Génétique et Développement de Rennes, IGDR-CNRS, UMR6290, Université de 10 Rennes 1, Rennes, France

11 * luisalberto.acuna@ucr.ac.cr,,506 2511-8616 


\section{ABSTRACT}

13 Studies on the anaerobic bacteria Porphyromonas, mainly focused on $P$. gingivalis, have 14 revealed new bacterial structures, metabolic pathways, and physiologic functionalities. 15 Porphyromonas are mainly described as being associated with mammals and involved in 16 chronic oral infections and secondary pathologies such as cancers or neurodegenerative 17 diseases. In this review, we collected and analyzed information regarding Porphyromonas 18 isolation sites and associated conditions and showed that Porphyromonas are detected in 19 numerous pristine and anthropic environments and that their host range appears wider than 20 previously believed, including aquatic animals, arthropods, and birds, even if their predominant 21 hosts remain humans, pets, and farm animals. Our analyses also revealed their presence in 22 multiple organs and in a substantial proportion of healthy contexts. Overall, the growing 23 numbers of microbiota studies have allowed unprecedented advances in the understanding of 24 Porphyromonas ecology but raise questions regarding their phylogenic assignment. In 25 conclusion, this systematic and meta-analysis provides an overview of current knowledge 26 regarding Porphyromonas ecological distribution and encourages additional research to fill the knowledge gaps to better understand their environmental distribution and inter- and intraspecies transmission.

KEYWORDS: Porphyromonas, host, organ, ecological distribution 


\section{Introduction}

The study of anaerobic bacteria, one of the oldest life forms, could enhance our knowledge regarding life origins [1]. These microorganisms are characterized by atmospheric oxygen intolerance [2], which hinders their isolation and culture [3]. In addition, their high nutritional requirements and slow growth [4] hamper evaluation of their metabolism, physiology, genetics, and ecology. Nevertheless, recent studies of animal and environmental microbiota have emphasized the importance of generating and integrating knowledge about anaerobic microorganisms $[5,6]$ owing to their prevalence [7] and roles in microbial communities $[1,8]$.

The Bacteroidetes phylum is predominant among human [9] and veterinary-associated microbiota [10] and, to a lower extent, in environmental communities [11]. This group exhibits novel features [12] such as their type IX secretion system [13,14] and type V fimbriae [15], both described for the first time in genus Porphyromonas. In 1921, Oliver and Wherry described black colonies on solid medium containing blood and proposed the name Bacteroides melaninogenicum [16]. In the 1970s and 1980s, this species was divided into three subspecies: B. m. melaninogenicus, B. m. intermedius, and B. m. asaccharolyticus [17] along with two others termed B. m. macacae [18] and B. m. levii [19]. This group was then renamed Bacteroides levii, B. macacae, and B. asaccharolyticus and the latter subsequently subdivided into two subgroups: B. asaccharolyticus and B. gingivalis [19,20], and a fifth species, Bacteroides endodontalis, was later described [21].

In 1988, Shah and Collins proposed creating a new genus, Porphyromonas, to group Porphyromonas asaccharolytica, P. gingivalis, and P. endodontalis [22]; subsequently, both Porphyromonas macacae [23] and Porphyromonas levii [24] were reclassified into this genus. The taxonomy of $P$. macacae was confusing until the mid 1990s, with two close species designated as P. macacae isolated in 1980 from macaques [18] and P. salivosa isolated in 1987 from cats [25]. These were considered as representing two distinctive heterotypic biovars $[23,26,27]$, but are now considered a single species [28,29].

Between 1992 and 1994, six new species were described: P. circumdentaria [28], P. canoris [30], P. cangingivalis [31], P. crevioricanis, and P. gingivicanis [32]. Finally, a sixth nonpigmented species initially called Oribaculum catoniae [33] was renamed Porphyromonas catoniae [34]. In 2001, Fournier et al. divided $P$. gingivalis into $P$. gingivalis (human strains) and $P$. gulae (animal strains) [35]. Finally, eight new species completed the list: P. uenonis [36], P. somerae [37], P. bennonis [38], P. pasteri [39], P. pogonae [40], P. bronchialis [41], P. loveana [42], and P. katsikii [43]. Notably, Falsiporphyromonas endometrii, described in 
2014 [44], is considered as a Porphyromonas in this study. Moreover, P. canis [45], and P. cansulci [31] have been reassigned respectively to P. gingivicanis [46], and P. crevioricanis [47]. These changes may cloud the analysis of the species, especially when some recent publications still use the old names (e.g. see [48-50]).

Most of the described Porphyromonas species are associated with mammal oral microbiota and implicated in pathological processes such as periodontitis [46,50,51]. Recently, $P$. gingivalis has been cited in a number of studies for its possible role in orodigestive cancers [5254]. Other studies suggest contributions of $P$. somerae in endometrial cancer [55], $P$. asaccharolytica in colorectal cancer [56,57], and P. endodontalis in gastric adenocarcinoma [58]. Notably, P. pasteri was inversely correlated with cancer progression in oral squamous cell carcinoma [59].

In this context, the purpose of this review was to clarify the ecological distribution of Porphyromonas. To address this issue, we analyzed 844 studies, focusing on the sites (e.g., organ, host, and environment) and associated conditions (e.g. pathologies vs health) of isolation.

\section{Material and methods}

The literature search was conducted in accordance with the PRISMA [60] using a fourstep strategy (Figure S1):

\section{Question formulation and checking for existing reviews}

When searching for reviews summarizing knowledge on the Porphyromonas genus, their hosts, infected organs, and associated pathologies, we noted that apart from $P$. gingivalis, no literature review existed. To our knowledge, this review is the first on this subject.

\section{Searching and selecting the relevant studies}

Three databases, PubMed, Google Scholar and Google image were searched to retrieve all records relevant to the study. The search was limited to publications after 1988, date of Porphyromonas-Bacteroides separation, with the exception of 2 articles describing $P$. circumdentaria and P. macacae [18,20]. Documents regarding P. gingivalis in the human oral sphere were excluded. The search was performed using key terms [All fields] in various combinations using a Boolean search technique as follows: 1) "Porphyromonas" AND one of the 20 species (e.g. "Porphyromonas" AND "gulae"); 2) "P." AND one of the 20 species; 3) 
"Porphyromonas" NOT gingivalis; and 4) "Porphyromonas" OR "P." AND "gingivalis" NOT "oral".

Peer-reviewed studies were retrieved including scientific articles, poster $(n=4)$, abstracts, and conference proceedings along with theses. Review articles, opinions, editorials, and blogs were not included. Only studies written in English and French $(n=4)$ were considered. Relevant results were downloaded, and their reference lists manually checked to identify missing documents using the search terms mentioned above. Duplicate records were deleted. Finally, 844 unique studies were included.

\section{Data extraction}

Information was organized in synthesis tables (Table S1 to S5) that included the Porphyromonas species name, organ or ecosystem as well as host or place of isolation, study authors and publication year, sample types, and situation of isolation (pathology or health status). Both authors independently assessed each study. Due to their very large number, references relating to these tables are not cited in this text but in the additional tables.

\section{Data analysis}

Hosts were categorized into three large taxonomic groups: most frequently mentioned hosts (humans, pets, farm animals and monkeys), aquatic animals, and less common hosts like rodents, birds, and arthropods. Organs were categorized into 9 major categories (Figure S2). Porphyromonas species names received an acronym (e.g. GUL for $P$. gulae, Figure 1 and Table S1). For the meta-analysis, bioinformatics and statistical analyses were carried out. The number of publications associated with a specific host, organ, and pathology were calculated for each Porphyromonas. The number of cases could not be utilized as this information is missing in the vast majority of articles. The statistical analysis was carried out using R Studio 1.2.5029 and R packages for correlation map and network generation (corrplot [61] and corrr R [62]); factorial correspondence analysis [63], hierarchical clustering [64] (FactoMineR [65] and factoextra [66]) and graphics generation (webr [67], wordcloud [68], and ggplot2 [69]).

When nucleotide sequences were accessible, we checked the taxonomic assignment using BlastN or mapping against Porphyromonas $16 \mathrm{~S}$ and whole-genome in-house databases. For 16S rDNA analysis, sequences were extracted manually from each genome, the phylogenetic tree built using PhyML [70] (substitution model K80, bootstrap=20) based on MAFFT alignment [71] (algorithm: G-INS-1, scoring matrix: 200PAM/k=2), the evolutionary model 
selected by Modeltest [72] (TPM3 $+\mathrm{I}+\mathrm{G})$, and the corresponding distance matrix visualized using the superheat $\mathrm{R}$ package [73].

\section{Results and discussion}

\section{Information sources}

The 21 recognized Porphyromonas species are described in an extremely variable number of publications (Figure 1, Table S1). Over 90\% of the documents focused on $P$. gingivalis in human oral pathologies. Consequently, the vast majority of current knowledge about Porphyromonas actually relates to human oral $P$. gingivalis, which is unlikely to represent the comprehensive genus biology. In the remaining 10\% (844 documents), 407 documents described Porphyromonas without attribution of species (termed $P$. spp.). The 437 articles with species descriptions are also distributed unevenly with over half limited to three species: $P$. asaccharolytica, $P$. gingivalis in animal or non-oral human isolates, and $P$. endodontalis. Conversely, only the initial description is available for two species ( $P$. bronchiolis and F. endometrii).

Additionally, publication frequency for each species is uneven (Figure S3). P. gingivalis (in the oral human context) registers hundreds of publications per year, whereas publication frequency for other Porphyromonas is variable and often minimal (averaging $<10$ papers annually). Such differences lead to a bias in the knowledge of Porphyromonas biology, with little if any information being produced for 20 non- $P$. gingivalis species. Nevertheless, we observed a general trend of increased publication frequencies since 2014, which corresponds to the application of next generation sequencing (NGS) in Porphyromonas studies (Figure S4). This technology has become an invaluable tool for their ecological study, as discussed below.

\section{Environmental Porphyromonas}

Notably, 103 scientific articles state the presence of Porphyromonas in environmental samples, in the vast majority with no species assignment except in 13 articles that proposed a species name based on the "best match" (Table S2). To verify these "best hits", we performed a new BlastN search and confirmed only $P$. gingivalis found on indoor climbing walls [74] and P. asaccharolytica in cow manure [75] whereas for three studies [76-78], we identified Macellibacteroides fermentans and Fermentimonas caenicola, respectively instead of Porphyromonas. However, most studies do not provide access to raw data and taxonomic designation cannot be verified. This highlights the importance of depositing sequencing data in 
164 open databases to allow reproducibility and re-analysis, with the fast-growing databases

165

166

167

168

169

170

171

172

173

174

175

176

177

178

179

180

181

182

183

184

185

186

187

188

189

190

191

192

193

194

195

196 enabling updates of the results. Moreover, when the "best hits" results are low, especially in the Porphyromonadaceae family for which taxonomy is frequently revised [79], it is therefore preferable to limit the description to the genus level. Owing to such possible errors in species assignment and lack of verification capability, we chose to consider environmental Porphyromonas as unknown species ( $P$. spp.).

A non-exhaustive description of the environmental diversity of Porphyromonas is presented in Figure 2 and Table S2. In pristine environments (27\%), Porphyromonas have been isolated from air samples (4\%); from soils (10\%) like agricultural lands and crops, alpine meadows, sediments and subseafloor, and in fresh- and sea- water (13\%). In anthropogenic environments (73\%), Porphyromonas have been detected in healthcare facilities as well as in indoor buildings and transport systems that constitute potential sites for microbial transmission between human and animal populations. Additionally, Porphyromonas were detected in various personal use objects. Finally, the most important source of environmental Porphyromonas derives from waste-management settings.

In summary, the environmental component of Porphyromonas is far from negligible. In some studies, Porphyromonas constitute "rare taxons" $(<1 \%)$ whereas in others they are abundant and described as part of the "core microbiome". Such environmental detection of Porphyromonas raises issues including whether they result from cross-contamination or are persistent in the environment or continually transmitted by oral and/or fecal material. These questions are inherent in all studies carried out by detecting DNA (PCR or NGS) that do not guarantee viability of the identified bacteria.

This review does not answer these questions but suggests that Porphyromonas have a capacity to persist in pristine and man-polluted environments, indicative of resistance to stressors such as atmospheric oxygen, UV radiation, or nutrient depletion, possibly via dormancy mechanisms leading to viable non-cultivable forms (VBNCs). It is also possible that in free-form, biotic interactions are harmful to Porphyromonas as these are not very competitive but in favorable situations such as biofilms, these bacteria are protected in a nutrient-rich microenvironment and may benefit from cooperation with other bacteria to maintain and/or thrive. Thus, environmental niches may be temporarily utilized by Porphyromonas, which then re-colonize and re-infect human or animal hosts.

\section{Host-associated Porphyromonas}


All Porphyromonas species, except for P. bronchialis and Falsiporphyromonas described only a few times, are detected in both disease and health conditions, in various proportions (Figure 3). Until 2012, Porphyromonas research had been focused on clinical microbiology and therefore biased toward pathological contexts with scarce descriptions in healthy contexts. This bias gradually disappeared concomitant with recent "without a priori" NGS studies that reported proportions of Porphyromonas spp. (P. spp., Figure S3) at $58.7 \%$ in healthy states versus $41.3 \%$ in disease conditions. This may be interpreted as these species constituting not true pathogens (according to Pasteur or Koch) but rather key bacteria ("keystone pathogen" or "alpha bug theory" [80,81]), orchestrating, even at low abundance, host immune response or serving as pathobionts ("bacterial passengers theory" [82]) that profit from altered homeostasis to thrive and trigger disease. Evaluation of the frequency of the major pathologies described for all species (Figure 4) reveals the preponderance of inflammatory diseases (suffix "-itis"), followed by cancers, degenerative and autoimmune diseases. These observations confirm a complex pathological pattern for Porphyromonas including an assortment of primary diseases and secondary morbidities.

In the literature, Porphyromonas host range is often dichotomic with opposing human and veterinary strains (e.g. see [83-85]), which may be interpreted as host specificity. However, it is important to reassess host range to address several major epidemiological issues including whether two or more Porphyromonas species can cohabite within a single microbiota, whether zoonosis is possible, and, if so, whether this provokes colonization, infection, adaptation, and propagation to new hosts or only transitory infection. Answers to these questions are necessary

218 to assess the possible threat to public health and food safety. For example, the presence of Porphyromonas in bovine milk has been described $[86,87]$ but it remains unknown whether its consumption may result in exogenous transmission. The possibility of Porphyromonas transfer between humans and pets is also unresolved. In order to reexamine Porphyromonas host range, we classified all animal isolation sources as minority/newly cited or main/historically known hosts, as follows.

\section{Minor or newly cited hosts of Porphyromonas}

Minor Porphyromonas hosts include aquatic wildlife (Table S3), arthropods, birds, small and/or wild mammals (Table S4). Briefly, in aquatic wildlife, Porphyromonas can survive and multiply in amoebas and endure physical and chemical stresses in their cysts. This 
facilities [88]. Marine life interactions have been noted in ciliates, corals, copepods, and oysters,

231 playing a possible role in Porphyromonas survival and potential transfer along the food chain,

232 as these bacteria are also found in fish, cetaceans, and penguins. This presence in aquatic

233 animals should be contextualized with their presence in pristine aquatic environments.

234 Porphyromonas were also detected in intestinal microbiota of arthropods (ectoparasites and

235 insects), in birds' intestinal and respiratory microbiota and appears frequent in the oral, genital,

236 anal, ocular, and nasal microbiota of wild and captive marsupials and mammals.

Frequent or frequently studied hosts of Porphyromonas

The major studied hosts all constitute mammals; in descending order: humans, dogs, cats, cattle, sheep, pigs, and monkeys. Using a contingency table for each Porphyromonas species phenotypic marker (health status, host, and organ, Table S1), significant correlations were visualized as a correlogram (Figure 5A) which revealed six isolated species, alone or in pairs. With the exception of $P$. levii, we suspect that this was largely due to the small number of publications (from one to six). The segregated species are as follows.

P. levii. Previously known as Bacteroides melaninogenicus subsp. levii then as Bacteroides levii [19] and reclassified as Porphyromonas in 1995 [24]. To avoid confusion, only publications after 1995 were considered for this species. However, some publications after 1995 still used the old Bacteroides levii name [89] or the terminology P. levii-like organisms (PLLO) [90,91], which might correspond to P. somerae [27,37,92]. For example, only one publication recorded $P$. levii in human vaginitis [93], a typical isolation site of $P$. somerae; this may therefore be a case of misidentification. Considering only accurate $P$. levii designations, we found that this species is quite specific to ovine infections [94] (Table S1). Despite its high prevalence, $P$. levii distribution within lesions suggests its role as a secondary colonizer rather than a main etiologic agent [95]. Additionally, in some cases, its presence in non-affected animals has been described $[96,97]$. As this species was initially isolated from healthy cattle rumen $[19,98]$ and is occasionally re-detected in this organ $[99,100]$, it can be hypothesized that the skin and genital colonization might be due to fecal contamination and/or hematogenous propagation [101].

Falsiporphyromonas endometrii. Originally isolated from cow endometrium [44] and in intestinal microbiota from sows, this species had been relegated to a new genus at the time of 
this publication as its phylogenetic distance from other Porphyromonas was deemed excessive.

264 However, rebuilding the rRNA 16S tree and distance matrix (Figures 5B \& 5C) indicated a Porphyromonas typical identity percentage. We therefore considered Falsiporphyromonas as a Porphyromonas in the absence of an official reclassification. Moreover, searching against BLAST gave Porphyromonas sp. 2069 and 2070 along with P. levii [102] and Porphyromonas sp. clone 1M9 [103] as best hits.

P. katsikii. Published only once after its isolation from sheep with pneumonia. BLAST search using its 16S sequence (accession number: KM360064) revealed four hits (99\% identity) corresponding to uncultured Porphyromonas sp. isolated from the uterus of healthy or metric cows [97].

P. loveana. Cited in three articles, two of which recorded five strains in Australian marsupials and one defining two strains in New Zealand sheep. Only partial 16S gene sequences are available from the Australian strains that form an Oceania endemic group (97 to 100\% identity).

$P$. pogonae. Described in six articles, first isolated from different polymicrobial infections in Pogona [104]. This species has also been described from the wounds of a crowned crane (Balearica sp.) and in human infections [40,105-107].

P. bronchialis. Only the initial description article for this species is available as a source of information, including four strains isolated from bronchial liquid from a single patient [41]. No nucleic acid sequence is available.

For the remaining 15 species, correspondence analysis using a host contingency table (Figure 6A) revealed a clear separation in 4 clusters (axis 1, 80\% variance) between species dominant in human versus those of pets (Figure 6B):

Cluster 1 contains five species essentially described in humans: P. uenonis and P. somerae yet described in cattle infections [102,108], and P. asaccharolytica, $P$. catoniae, and $P$. endodontalis also described in pets, cattle, and primates.

294 (Cluster 2). However, P. pasteri (exclusively human) and P. bennonis (also cited in pig feces 295 [109]) are poorly studied (Figure 1). 
P. gulae, $P$. gingivalis closest relative (Figure 5B), grouped in Cluster 4 with P. macacae, $P$. canoris, and $P$. circumdentaria. As such, $P$. gingivalis and $P$. gulae appear as two ecotypes separated according to number of human and canine cases $[110,111]$ and distinguishable by the catalase test, $P$. gulae being positive and P. gingivalis negative [35]. Nevertheless, these two species contain similar virulence factors [85,112]. P. gulae can invade human cells in vitro [113] but with less adherence to human cells than $P$. gingivalis [114].

Some articles recorded $P$. gulae in humans. A study showed that its high prevalence in aborigines, may be associated with their traditional diet (primate meat) and/or use of capuchin as pets, facilitating transmission from primate to human. Notably, the authors hypothesize that $P$. gulae may be a competitor of $P$. gingivalis and that both species might rarely or inefficiently cohabit [115]. Yet, both species have been identified in biofilms from periodontitis [116]. Moreover, $P$. gulae have been detected in the oral cavities and skin of dog owners, which may potentially result from dog-to-human transfer [117,118], poster). Conversely, $P$. gulae was not detected in cat owners [119]. Additionally, $P$. gulae have been reported in fecal samples from patients with colorectal cancer [120] and with $P$. gingivalis in cervical microbiota from infertile women [121]. It is difficult to synthesize colonization of humans by $P$. gulae as few studies exist and as this species is highly similar to $P$. gingivalis. Therefore, several questions remain, such as whether the absence of co-detection is legitimate or owing to inadequate analyses that underestimate the presence of $P$. gulae in human microbiota, or, if such cohabitation is indeed rare. However, if both species can coexist in humans, the issue of $P$. gulae zoonotic transfer (Table S1; Fig 6B) should be addressed considering the involvement of Porphyromonas in oncologic and neurologic diseases.

Correspondingly, $P$. gingivalis has been reported in animal oral cavities either with or without periodontitis, and in bite wounds and fecal material (Table S1). However, as $P$. gingivalis remains isolated predominantly from human medicine contexts, its study in animals is therefore necessary to elucidate whether these reports correspond to opportunistic colonization, occasional and transitory transfer from human to animals, or whether this species is not exclusively human-based.

All canine and feline species clustered with P. gulae (Cluster 4, Fig 6B), and are also occasionally reported in humans (from 6 to $15 \%$ of cases). P. canoris in human skin (Table S1), $P$. circumdentaria in healthy liver biopsies [122] and in fecal and genital microbiomes 
$[27,125,126]$, which was expected as this species is frequently identified in pet oral microbiota (Table S1).

The last cluster (Cluster 3, Fig 6B) groups $P$. gingivicanis, $P$. crevioricanis, and $P$. cangingivalis, originally described in dog oral microbiota but also detected in cat, human, and cattle pathologies (Table S1).

In conclusion, we found that Porphyromonas was present in almost all animal orders. This information raises new questions about their epidemiology and host-specificities. Indeed, the only studies regarding Porphyromonas host-to-host transmission are between humans, specifically interfamily transmission [127-135], and from oral sources, with saliva as the vehicle [136]. Epidemiological studies of Porphyromonas in animals do not appear to be a priority. However, domestic mammals (cattle, cats, and dogs) live in very close association with their owners and all their secretions (saliva, urine) are present in the everyday environment. This review thus highlights the necessity for a rigorous reassessment of Porphyromonas host specificities.

Moreover, although numerous studies have associated these bacteria with clinical observations, mostly in human dentistry, NGS studies in the past decade have revealed a much wider host range. Prior to these approaches, classical culture-based have been insufficient to broaden our knowledge regarding Porphyromonas host diversity, as these bacteria are fastidious, slow growing, and produce low biomass. The presence of Porphyromonas across numerous and varied environments renders it necessary to determine whether they constitute generalist environmental pathogens or specialized opportunists that may briefly transfer to other reservoirs. To explore these issues, we reviewed Porphyromonas distribution in different organs, both in healthy and pathological conditions.

\section{Organ distribution of Porphyromonas}

The distribution of Porphyromonas in cellular compartments is likely indicative of their colonization mechanism. To summarize the information, we classified the anatomical sites in nine categories with associated pathological or healthy conditions (Figure S2).

The objective of this investigation was to clarify and extend our knowledge regarding their cellular specificities. Generally, the scientific literature simplifies the findings and usually describes Porphyromonas species as expressly localized in specific body sites; e.g. P. gingivalis and $P$. endodontalis in the oral cavity, $P$. uenonis in the gut, and $P$. somerae in the genital tract. A contingency table registering the number of articles citing each of the nine organ categories 
was used to generate a hierarchical clustering and waffle plots (Figure 7). Analysis of these plots revealed that none of the 15 species of Porphyromonas exhibits organ specificity but rather preferences for certain anatomical sites.

P. asaccharolytica and P. gingivalis, the two most published Porphyromonas (Figure 1), are the only species to be found in all 9 sites, albeit at variable proportion. This suggested that the number and diversity of publications constitute important factors that likely bias the results of less-reported species. Nevertheless, currently available data reveal three different types of profiles. The first cluster (Figure 7) corresponds to "multiple organ" behavior involving $P$. asaccharolytica, $P$. somerae, $P$. bennonis, and $P$. uenonis. The second cluster includes $P$. macacae, $P$. cangingivalis, $P$. canoris, $P$. circumdentaria, and $P$. crevioricanis found in the oral cavity and skin. As these species are often isolated from pets, the hypothesis of secondary opportunistic infection of bite and scratches wounds by oral Porphyromonas after licking represents the most obvious route of transmission. Finally, the third group (Figure 7) includes essentially oral bacteria such as $P$. gulae, $P$. gingivalis, $P$. endodontalis, $P$. gingivicanis, $P$. catoniae, and $P$. pasteuri, which are also occasionally detected in other organs.

This descriptive analysis suggested the capacity of Porphyromonas species to propagate in and on different body sites, thus allowing consideration of primary sites and various invasion routes allowing secondary colonization. However, the research needed to understand these routes of transmission is lacking. Although numerous analyses have been published regarding Porphyromonas adhesion to host cells, these are predominantly of $P$. gingivalis; complementary investigation must therefore be achieved for the other species. Mechanisms that allow the establishment and maintenance of an intracellular lifestyle along with the diversity of intracellular compartments used for Porphyromonas replication and crossing of host barriers need to be specifically studied in all species if possible. This knowledge would allow more precise definition of the threshold between Porphyromonas commensalism and pathogenicity, which constitutes a relevant issue as demonstrated in this review because these bacteria belong to the host microbiota and can therefore be considered commensal but can become pathogenic when they escape from their original niche or when their growth rate increases.

\section{Concluding remarks}

The initial objective of this review was to summarize the knowledge regarding the host and organ range in addition to associated conditions (pathological or healthy) for the 21 species of the Porphyromonas genus currently described. However, the marked heterogeneity in the 
394 knowledge between $P$. gingivalis, the predominantly reported species with several studies per 395 week and that of the large majority of species, associated with only 5 to 10 articles annually, 396 along with the "exotic" species such as P. bronchialis or P. katsikii that have accumulated $<5$ 397 papers over the past 20 years, was immediately apparent. We also observed that approximately 398 half of the eligible studies described Porphyromonas spp. This inevitably resulted in "gray 399 areas" and biases that rendered the interpretation of the results difficult and imprecise. 400 However, the number of cases of cancers or systemic diseases associated directly or indirectly 401 with Porphyromonas is accumulating, in addition to the previously well documented cases of 402 infections and inflammations. A more thorough understanding of this bacterial genus therefore 403 appears important for enhancing human and veterinary health with various complementary 404 experiments, as discussed throughout this review, appearing necessary to clarify the taxonomic 405 descriptions and refine the biological characterizations of the less-reported species. The 406 summary schematic (Figure 8) showing their presence in numerous environments, hosts, and 407 biological niches is thus incomplete and biased but nevertheless indicates the extremely 408 widespread albeit poorly studied ecological distribution of this important bacterial genus. 409 


\section{$410 \quad$ Funding details}

411 L.A-A. was supported by Vicerrectoría de Investigación from Universidad de Costa Rica (VI412 UCR) under grants 803-B8-118 and 803-B9-455. Additionally, this work was supported by the 413 mobility program from l'Institut Français d'Amérique Centrale (IFAC). Neither VI-UCR nor 414 IFAC had any role in the design of the study and collection, analysis, and interpretation of data, 415 nor in writing the manuscript.

416

\section{Disclosure statement}

418 The authors declare that they have no competing interests.

419 
421 Figure 1. Number of documents (scientific articles, doctoral theses, posters, and conference abstracts; total $=437$ ) related to Porphyromonas species. $P$. gingivalis studied in the human oral biotope (GIN_o) does not appear because its records exceeded 8000 documents. Only records citing this species in non-human (animals) or human non_oral contexts (GIN_no) are represented. Records for which the species was not identified, i.e. Porphyromonas spp. (P. spp.), are not presented (407 records).

Figure 2. Pie chart sub-categorized with a donut diagram representing the proportion of the different environments in which Porphyromonas were detected. Pristine environments correspond to undisturbed ecosystems and thus unmodified by human activity as opposed to anthropogenic environments, reflecting those modified by human activities.

Figure 3. Polar chart representing the proportion of records associated with each Porphyromonas species along with Porphyromonas spp. and either healthy (green) or disease (red) conditions. The total number of records corresponds to that presented in Figure 1. For $P$. gingivalis, the oral human records (GIN_o) were totaled using PubMed abstracts whereas oral and non-oral animal cases in addition to non-oral human cases (GIN_no) were fully analyzed similarly to the other Porphyromonas species.

Figure 4. Word cloud representing all the pathologies and/or keywords associated with all Porphyromonas species as recorded in this analysis. The word size corresponds its number and is proportional to the total of pathologies/keywords mentioned; colors are used in accordance with the word size (from the most frequent to the least frequent: warm colors to cool colors).

Figure 5. Relationship between Porphyromonas species phenotypic traits and phylogenetic relatedness. A. Top panel. Correlogram displaying the phenotypic correlation matrix (organ, host distribution, and pathology association). Color intensity and dot size indicate the Pearson coefficient values from light (0) to dark (1). Bottom panel. Correlation network to visualize pairwise correlations between Porphyromonas species inside each of the three clusters presented in the top panel. Each edge stands for a Spearman correlation $>0.90(p<0.05)$. Color of the edges is related to the coefficient of correlation from light to dark. Isolated species, alone 
453 brackets corresponds to the number of strains used to generate each consensus sequence by 454 species. Colors represent the clusters of correlograms in panel A. P. bronchialis is absent as its $45516 \mathrm{~S}$ sequence is not available. C. Distance matrix used for the 16S rDNA phylogenetic tree in 456 B

458 Figure 6. Major host distribution for the three Porphyromonas species clusters identified based 459 on phenotypic traits. A. Factorial correspondence analysis of Porphyromonas species according 460 to the number of cases for each category of major hosts (see details in the text). B. Host-range 461 repartition detailed for each Porphyromonas species and each identified cluster. Green, Cluster 462 I; red, Cluster 2; blue, Cluster 3; purple, Cluster 4.

464 Figure 7. Hierarchical clustering of Porphyromonas species according to the isolation site or 465 organ separated by category (see details in Figure S4). The waffle charts reflect the relative 466 abundances in each organ group described above (one block $=1 \%$ ).

Figure 8. Overview of Porphyromonas isolation and/or description in all habitats including the environment and all its hosts. Within hosts, organs or body sites from which Porphyromonas have been described are detailed.

Supplemental Figure S1. Preferred reporting elements for systematic reviews and metaanalyzes (PRISMA), flowchart and checklist detailing documents search (from 01-1988 to 092019) and selection process applied in this systematic review and meta-analysis about Porphyromonas ecology.

Supplemental Figure S2. Categories used in this meta-analysis corresponding to the isolation site or organ in which Porphyromonas species have been described; a full description of all terms is presented for each category.

Supplemental Figure S3. Number of records included in this study for each Porphyromonas species by year from 01-1988 until 09-2019. For P. gingivalis, the oral human records (GIN_o) were totaled using PubMed abstracts whereas oral and non-oral animal cases in addition to nonoral human cases (GIN_no) have been referenced based on full records for the meta-analysis, as for the other Porphyromonas species. 
487 Supplementary Figure S4. Number of records according to method of Porphyromonas 488 identification and year. For each record included in this study, the identification method for any 489 Porphyromonas isolate was classified into four categories: traditional identification and 490 culturomics, immunologic or other wet lab method, specific 16S rDNA PCR to identify 491 Porphyromonas species and related methods, and microbiota and metagenomics studies (NGS). 492 


\section{References}

494 [1] W.F. Martin, F.L. Sousa, Early Microbial Evolution: The Age of Anaerobes, Cold Spring Harb Perspect Biol. 8 (2015) a018127. https://doi.org/10.1101/cshperspect.a018127.

[2] I. Slesak, M. Kula, H. Slesak, Z. Miszalski, K. Strzalka, How to define obligatory anaerobiosis? An evolutionary view on the antioxidant response system and the early stages of the evolution of life on Earth, Free Radic Biol Med. (2019). https://doi.org/10.1016/j.freeradbiomed.2019.03.004.

[3] E. Nagy, L. Boyanova, U.S. Justesen, How to isolate, identify and determine antimicrobial susceptibility of anaerobic bacteria in routine laboratories, Clin Microbiol Infect. 24 (2018) 1139-1148. https://doi.org/10.1016/j.cmi.2018.02.008.

[4] P. Hugon, J.C. Dufour, P. Colson, P.E. Fournier, K. Sallah, D. Raoult, A comprehensive repertoire of prokaryotic species identified in human beings, Lancet Infect Dis. 15 (2015) 1211-1219. https://doi.org/10.1016/s1473-3099(15)00293-5.

[5] B. La Scola, S. Khelaifia, J.C. Lagier, D. Raoult, Aerobic culture of anaerobic bacteria using antioxidants: a preliminary report, Eur J Clin Microbiol Infect Dis. 33 (2014) 1781-1783. https://doi.org/10.1007/s10096-014-2137-4.

[6] L.M. Mauerhofer, P. Pappenreiter, C. Paulik, A.H. Seifert, S. Bernacchi, S.K.R. Rittmann, Methods for quantification of growth and productivity in anaerobic microbiology and biotechnology, Folia Microbiol (Praha). 64 (2019) 321-360. https://doi.org/10.1007/s12223-018-0658-4.

[7] D.L. Church, Selected Topics in Anaerobic Bacteriology, Microbiol Spectr. 4 (2016). https://doi.org/10.1128/microbiolspec.DMIH2-0015-2015.

[8] I.A. Podolsky, S. Seppala, T.S. Lankiewicz, J.L. Brown, C.L. Swift, M.A. O’Malley, Harnessing Nature's Anaerobes for Biotechnology and Bioprocessing, Annu Rev Chem Biomol Eng. 10 (2019) 105-128. https://doi.org/10.1146/annurev-chembioeng-060718-030340.

[9] G. Gibiino, L.R. Lopetuso, F. Scaldaferri, G. Rizzatti, C. Binda, A. Gasbarrini, Exploring Bacteroidetes: Metabolic key points and immunological tricks of our gut commensals, Dig Liver Dis. 50 (2018) 635639. https://doi.org/10.1016/j.dld.2018.03.016.

[10] P. Deng, K.S. Swanson, Gut microbiota of humans, dogs and cats: current knowledge and future opportunities and challenges, Br J Nutr. 113 Suppl (2015) S6-17. https://doi.org/10.1017/s0007114514002943.

[11] J.M. Grondin, K. Tamura, G. Dejean, D.W. Abbott, H. Brumer, Polysaccharide Utilization Loci: Fueling Microbial Communities, J Bacteriol. 199 (2017). https://doi.org/10.1128/jb.00860-16.

[12] P. Manfredi, F. Lauber, F. Renzi, K. Hack, E. Hess, G.R. Cornelis, New iron acquisition system in Bacteroidetes, Infect Immun. 83 (2015) 300-310. https://doi.org/10.1128/iai.02042-14.

[13] M.J. McBride, Bacteroidetes Gliding Motility and the Type IX Secretion System, Microbiol Spectr. 7 (2019). https://doi.org/10.1128/microbiolspec.PSIB-0002-2018.

[14] K. Sato, M. Naito, H. Yukitake, H. Hirakawa, M. Shoji, M.J. McBride, R.G. Rhodes, K. Nakayama, A protein secretion system linked to bacteroidete gliding motility and pathogenesis, Proc. Natl. Acad. Sci. U. S. A. 107 (2010) 276-281. https://doi.org/10.1073/pnas.0912010107.

[15] T. Onoe, C.I. Hoover, K. Nakayama, T. Ideka, H. Nakamura, F. Yoshimura, Identification of Porphyromonas gingivalis prefimbrilin possessing a long leader peptide: possible involvement of trypsin-like protease in fimbrilin maturation, Microb Pathog. 19 (1995) 351-364.

[16] W.W. Oliver, W.B. Wherry, Notes on some bacterial parasites of the human mucous membranes, J. Infect. Dis. (1921) 341-344.

[17] S.M. Finegold, E.M. Barness, Proposal that the saccharolytic and asaccharolytic strains at present classified in the species Bacteroides melaninogenicus (Oliver and Wherry) should be reclassified in two species as Bacteroides melaninogenicus and Bacteroides asaccharolyticus, Int. J. Syst. Bacteriol. 27 (1977) 388391.

[18] J. Slots, R.J. Genco, Bacteroides melaninogenicus subsp. macacae, a new subspecies from monkey periodontopathic indigenous microflora, Int. J. Syst. Bacteriol. 30 (1980) 82-85. https://doi.org/10.1099/00207713-30-1-82.

[19] J.L. Johnson, L. V Holdeman, Bacteroides intermedius comb. nov. and descriptions of Bacteroides corporis sp. nov. and Bacteroides levii sp. nov, Int. J. Syst. Evol. Microbiol. 33 (1983) 15-25.

[20] A.L. Coykendall, F.S. Kaczmarek, J. Slots, Genetic heterogeneity in Bacteroides asaccharolyticus (Holdeman and Moore 1970) Finegold and Barnes 1977 (Approved Lists, 1980) and proposal of Bacteroides gingivalis sp. nov. and Bacteroides macacae (Slots and Genco) comb. nov., Int. J. Syst. Bacteriol. 30 (1980) 559-564. https://doi.org/10.1099/00207713-30-3-559.

[21] T.J.M. Van Steenbergen, A.J. Van Winkelhoff, D. Mayrand, D. Grenier, J. De Graaff, Bacteroides endodontalis sp. nov., an asaccharolytic black-pigmented Bacteroides species from infected dental root 
canals, Int. J. Syst. Evol. Microbiol. 34 (1984) 118-120.

[22] H.N. Shah, M.D. Collins, Proposal for reclassification of Bacteroides asaccharolyticus, Bacteroides gingivalis, and Bacteroides endodontalis in a new genus, Porphyromonas, Int. J. Syst. Evol. Microbiol. 38 (1988) 128-131.

[23] D.N. Love, Porphyromonas macacae comb. nov., a consequence of Bacteroides macacae being a senior synonym of Porphyromonas salivosa, Int. J. Syst. Evol. Microbiol. 45 (1995) 90-92.

[24] H.N. Shah, M.D. Collins, I. Olsen, B.J. Paster, F.E. Dewhirst, Reclassification of Bacteroides levii (Holdeman, Cato, and Moore) in the Genus Polphyromonas, as Porphyromonas levii comb. nov., Int. J. Syst. Bacteriol. 45 (1995) 586-588.

[25] D.N. Love, J.L. Johnson, R.F. Jones, A. Calverley, Bacteroides salivosus sp. nov., an Asaccharolytic, Black-Pigmented Species from Cats, Int. J. Syst. Bacteriol. 37 (1987) 307-309. https://doi.org/10.1099/00207713-37-4-307.

[26] M.E. Mulligan, D.M. Citron, R.Y. Kwok, E.J.C. Goldstein, Immunoblot Characterization of Porphyromonas species from infected dog and cat bite wounds in humans, CID. 25 (1997) S98-S99. https://doi.org/10.1086/516236.

[27] D.M. Citron, S. Hunt Gerardo, M.C. Claros, F. Abrahamian, D. Talan, E.J.C. Goldstein, S.H. Gerardo, M.C. Claros, F. Abrahamian, D. Talan, E.J.C. Goldstein, Frequency of Isolation of Porphyromonas Species from Infected Dog and Cat Bite Wounds in Humans and Their Characterization by Biochemical Tests and Arbitrarily Primed- Polymerase Chain Reaction Fingerprinting, Clin. Infect. Dis. 23 (1996) S77-82. https://doi.org/10.1093/clinids/23.supplement 1.s78.

[28] D.N. Love, G.D. Bailey, S. Collings, D.A. Briscoe, Description of Porphyromonas circumdentaria sp. nov. and reassignment of Bacteroides salivosus (Love, Johnson, Jones, and Calverley 1987) as Porphyromonas (Shah and Collins 1988) salivosa comb. nov., Int. J. Syst. Bacteriol. 42 (1992) 434 438. https://doi.org/10.1099/00207713-42-3-434.

[29] B.J. Paster, F.E. Dewhirst, I. Olsen, G.J. Fraser, Phylogeny of Bacteroides, Prevotella, and Porphyromonas spp. and related bacteria., J. Bacteriol. 176 (1994) 725-732. https://doi.org/10.1128/jb.176.3.725732.1994

[30] D.N. Love, J. Karjalainen, A. Ivlnervo, B. Forsblom, E. Sarkiala, G.D. Bailey, D.I. Wigney, H. JousimiesSomer, A. Kanervo, B. Forsblom, E. Sarkiala, G.D. Bailey, D.I. Wigney, H. Jousimies-Somer, Porphyromonas canoris sp. nov., an Asaccharolytic, Black-Pigmented Species from the Gingival Sulcus of Dogs, Int. J. Syst. Bacteriol. 44 (1994) 204-208. https://doi.org/10.1099/00207713-44-2-204.

[31] M.D. Collins, D.N. Love, J. Karjalainen, A. Kanervo, B. Forsblom, A. Willems, S. Stubbs, E. Sarkiala, G.D. Bailey, D.I. Wigney, et al., H. Jousimies-Somer, Phylogenetic analysis of members of the genus Porphyromonas and description of Porphyromonas cangingivalis sp. nov. and Porphyromonas cansulci sp. nov., Int. J. Syst. Bacteriol. 44 (1994) 674-679. https://doi.org/10.1099/00207713-44-4-674.

[32] M. Hirasawa, K. Takada, Porphyromonas gingivicanis sp. nov. and Porphyromonas crevioricanis sp. nov., isolated from beagles, Int J Syst Bacteriol. 44 (1994) 637-640. https://doi.org/10.1099/00207713-44-4637.

[33] L.V.H. Moore, W.E.C. Moore, Oribaculum catoniae gen. nov., sp. nov.; Catonella morbi gen. nov., sp. nov.; Hallella seregens gen. nov., sp. nov.; Johnsonella ignava gen. nov., sp. nov.; and Dialister pneumosintes gen. nov., comb. nov., nom. rev., anaerobic gram-negative bacilli from, Int. J. Syst. Evol. Microbiol. 44 (1994) 187-192.

[34] A. Willems, M.D. Collins, Reclassification of Oribaculum catoniae (Moore and Moore 1994) as Porphyromonas catoniae comb. nov. and emendation of the genus Porphyromonas, Int J Syst Bacteriol. 45 (1995) 578-581. https://doi.org/10.1099/00207713-45-3-578.

[35] D. Fournier, C. Mouton, P. Lapierre, T. Kato, K. Okuda, C. Menard, C. Ménard, Porphyromonas gulae sp. nov, an anaerobic, Gram-negative coccobacillus from gingival sulcus of various animal hosts, Int. J. Syst. Evol. Microbiol. 51 (2001) 1179-1189. https://doi.org/10.1099/00207713-51-3-1179.

[36] S.M. Finegold, M.L. Vaisanen, M. Rautio, E. Eerola, P. Summanen, D. Molitoris, Y. Song, C. Liu, H. Jousimies-Somer, Porphyromonas uenonis sp. nov., a pathogen for humans distinct from P. asaccharolytica and P. endodontalis, J. Clin. Microbiol. 42 (2004) 5298-5301. https://doi.org/10.1128/JCM.42.11.5298-5301.2004.

[37] P.H. Summanen, B. Durmaz, M.L. Vaisanen, C. Liu, D. Molitoris, E. Eerola, I.M. Helander, S.M. Finegold, Porphyromonas somerae sp. nov., a pathogen isolated from humans and distinct from Porphyromonas levii, J Clin Microbiol. 43 (2005) 4455-4459. https://doi.org/10.1128/jcm.43.9.4455-4459.2005.

[38] P.H. Summanen, P.A. Lawson, S.M. Finegold, Porphyromonas bennonis sp. nov., isolated from human clinical specimens, Int. J. Syst. Evol. Microbiol. 59 (2009) 1727-1732. https://doi.org/10.1099/ijs.0.001909-0.

[39] M. Sakamoto, D. Li, Y. Shibata, T. Takeshita, Y. Yamashita, M. Ohkuma, Porphyromonas pasteri sp. Nov., 
isolated from human saliva, Int. J. Syst. Evol. Microbiol. 65 (2015) 2511-2515.

https://doi.org/10.1099/ijs.0.000294.

[40] Y. Kawamura, S. Kuwabara, S.A. Kania, H. Kato, M. Hamagishi, N. Fujiwara, T. Sato, J. Tomida, K. Tanaka, D.A. Bemis, Porphyromonas pogonae sp. nov., an anaerobic but low concentration oxygen adapted coccobacillus isolated from lizards (Pogona vitticeps) or human clinical specimens, and emended description of the genus Porphyromonas Shah and Collins 1988, Syst. Appl. Microbiol. 38 (2015) 104-109. https://doi.org/10.1016/j.syapm.2014.11.004.

[41] T. Sato, J. Tomida, T. Naka, N. Fujiwara, A. Hasegawa, Y. Hoshikawa, J. Matsuyama, N. Ishida, T. Kondo, K. Tanaka, Porphyromonas bronchialis sp. nov. isolated from intraoperative bronchial fluids of a patient with non-small cell lung cancer, Tohoku J. Exp. Med. 237 (2015) 31-37.

[42] P.S. Bird, D.J. Trott, D. Mikkelsen, G.J. Milinovich, K.M. Hillman, P.C. Burrell, L.L. Blackall, Porphyromonas loveana sp. Nov., isolated from the oral cavity of Australian marsupials, Int. J. Syst. Evol. Microbiol. 66 (2016) 3771-3778. https://doi.org/10.1099/ijsem.0.000898.

[43] G. Filioussis, E. Petridou, E. Karavanis, J. Frey, Pyogranulomatous pneumonia in goats caused by an undescribed Porphyromonas species: "Porphyromonas katsikii” J Clin Microbiol. 53 (2015) 795-8. https://doi.org/10.1128/JCM.02682-14.

[44] K. Wagener, M. Drillich, S. Baumgardt, P. Kämpfer, H.J. Busse, M. Ehling-Schulz, Falsiporphyromonas endometrii gen. nov., sp. nov., isolated from the post-partum bovine uterus, and emended description of the genus Porphyromonas Shah and Collins 1988, Int. J. Syst. Evol. Microbiol. 64 (2014) 642-649. https://doi.org/10.1099/ijs.0.057307-0.

[45] Porphyromonas canis gene for 16S rRNA - Nucleotide - NCBI, (n.d.). https://www.ncbi.nlm.nih.gov/nuccore/AB034799.1 (accessed January 24, 2020).

[46] N.R. Krieg, W. Ludwig, J. Euzéby, W.B. Whitman, Phylum XIV. Bacteroidetes phyl. nov, in: N.R. Krieg, J.T. Staley, D.R. Brown, B.P. Hedlund, B.J. Paster, N.L. Ward, W. Ludwig, W.B. Whitman (Eds.), Bergey’s Manual ${ }^{\circledR}$ Syst. Bacteriol. Vol. Four Bacteroidetes, Spirochaetes, Tenericutes (Mollicutes), Acidobacteria, Fibrobacteres, Fusobacteria, Dictyoglomi, Gemmatimonadetes, Lentisphaerae, Verrucomicrobia, Chlamydiae, Planctomycetes, Springer New York, New York, NY, 2010: pp. 25-469. https://doi.org/10.1007/978-0-387-68572-4 3.

[47] F.E. Dewhirst, E.A. Klein, E.C. Thompson, J.M. Blanton, T. Chen, L. Milella, C.M.F. Buckley, I.J. Davis, M.L. Bennett, Z. V. Marshall-Jones, The canine oral microbiome, PLoS One. 7 (2012) 1-12. https://doi.org/10.1371/journal.pone.0036067.

[48] Y. Koyata, K. Watanabe, T. Toyama, S. Haruka, N. Hamada, Purification and characterization of a fimbrial protein from Porphyromonas salivosa ATCC 49407, J. Vet. Med. Sci. 81 (2019) 916-923. https://doi.org/10.1292/jvms.19-0067.

[49] J.H.Y.J.Y.H. Lee, J.H. Moon, J.I. Ryu, S.W. Kang, K.H. Kwack, J.H.Y.J.Y.H. Lee, Antibacterial effects of sodium tripolyphosphate against Porphyromonas species associated with periodontitis of companion animals, J Vet Sci. 20 (2019) e33. https://doi.org/10.4142/jvs.2019.20.e33.

[50] A. do Nascimento Silva, E.D. de Avila, V. Nakano, M.J. Avila-Campos, Pathogenicity and genetic profile of oral Porphyromonas species from canine periodontitis, Arch. Oral Biol. 83 (2017) $20-24$. https://doi.org/10.1016/j.archoralbio.2017.07.001.

[51] C. Damgaard, A.K. Danielsen, C. Enevold, L. Massarenti, C.H. Nielsen, P. Holmstrup, D. Belstrom, Porphyromonas gingivalis in saliva associates with chronic and aggressive periodontitis, J Oral Microbiol. 11 (2019) 1653123. https://doi.org/10.1080/20002297.2019.1653123.

[52] I. Lafuente Ibáñez de Mendoza, X. Maritxalar Mendia, A.M. García de la Fuente, G. Quindós Andrés, J.M. Aguirre Urizar, Role of Porphyromonas gingivalis in oral squamous cell carcinoma development: A systematic review, J. Periodontal Res. (2019) jre.12691. https://doi.org/10.1111/jre.12691.

[53] I. Olsen, Ö. Yilmaz, Possible role of Porphyromonas gingivalis in orodigestive cancers, J. Oral Microbiol. 11 (2019). https://doi.org/10.1080/20002297.2018.1563410.

[54] Y. Zhou, G.H. Luo, Porphyromonas gingivalis and digestive system cancers, World J. Clin. Cases. 7 (2019) 819-829. https://doi.org/10.12998/wjcc.v7.i7.819.

[55] E. Caselli, I. Soffritti, M. D’Accolti, I. Piva, P. Greco, G. Bonaccorsi, Atopobium vaginae and Porphyromonas somerae induce proinflammatory cytokines expression in endometrial cells: A possible implication for endometrial cancer? Cancer Manag. Res. 11 (2019) 8571-8575. https://doi.org/10.2147/CMAR.S217362.

[56] N.T. Baxter, M.T. Ruffin, M.A.M. Rogers, P.D. Schloss, Microbiota-based model improves the sensitivity of fecal immunochemical test for detecting colonic lesions, Genome Med. 8 (2016) 37. https://doi.org/10.1186/s13073-016-0290-3.

[57] Z. Dai, O.O. Coker, G. Nakatsu, W.K.K.K. Wu, L. Zhao, Z. Chen, F.K.L.L. Chan, K. Kristiansen, J.J.Y.Y. Sung, S.H. Wong, J. Yu, Multi-cohort analysis of colorectal cancer metagenome identified altered 
bacteria across populations and universal bacterial markers, Microbiome. 6 (2018) 70. https://doi.org/10.1186/s40168-018-0451-2.

[58] Y.L. Hu, W. Pang, Y. Huang, Y. Zhang, C.J. Zhang, The Gastric Microbiome Is Perturbed in Advanced Gastric Adenocarcinoma Identified Through Shotgun Metagenomics, Front. Cell. Infect. Microbiol. 8 (2018) 433. https://doi.org/10.3389/fcimb.2018.00433.

[59] C.Y. Yang, Y.M. Yeh, H.Y. Yu, C.Y. Chin, C.W. Hsu, H. Liu, P.J. Huang, S.N. Hu, C.T. Liao, K.P. Chang, Y.L. Chang, Oral microbiota community dynamics associated with oral squamous cell carcinoma staging, Front. Microbiol. 9 (2018). https://doi.org/10.3389/fmicb.2018.00862.

[60] D. Moher, A. Liberati, J. Tetzlaff, D.G. Altman, Preferred reporting items for systematic reviews and metaanalyses: the PRISMA statement., PLoS Med. 6 (2009) e1000097. https://doi.org/10.1371/journal.pmed.1000097.

[61] T. Wei, V. Simko, R package "corrplot": Visualization of a Correlation Matrix, (2017). https://github.com/taiyun/corrplot.

[62] M. Kuhn, S. Jackson, J. Cimentada, R package “corrr”: Correlations in R, (2020). https://cran.rproject.org/package $=$ corrr.

[63] N. Sourial, C. Wolfson, B. Zhu, J. Quail, J. Fletcher, S. Karunananthan, K. Bandeen-Roche, F. Béland, H. Bergman, Correspondence analysis is a useful tool to uncover the relationships among categorical variables, J. Clin. Epidemiol. 63 (2010) 638-646. https://doi.org/10.1016/j.jclinepi.2009.08.008.

[64] A.S. Vijaya, R. Bateja, A Review on Hierarchical Clustering Algorithms, J. Eng. Appl. Sci. 12 (2017) 7501-7507.

[65] S. Lê, J. Josse, F. Husson, FactoMineR: A Package for Multivariate Analysis, J. Stat. Softw. 25 (2008) 118. https://doi.org/10.18637/jss.v025.i01.

[66] A. Kassambara, F. Mundt, R package "factoextra": Extract and Visualize the Results of Multivariate Data Analyses, (2020). https://cran.r-project.org/package=factoextra.

[67] K.-W. Moon, T. Martino, R package "webr": Data and Functions for Web-Based Analysis, (2020). https://cran.r-project.org/package=webr.

[68] I. Fellows, R package "wordcloud": Word Clouds, (2018). https://cran.r-project.org/package=wordcloud.

[69] H. Wickham, ggplot2: Elegant Graphics for Data Analysis, Springer-Verlag New York, 2016. https://ggplot2.tidyverse.org.

[70] S. Guindon, J.-F. Dufayard, V. Lefort, M. Anisimova, W. Hordijk, O. Gascuel, New algorithms and methods to estimate maximum-likelihood phylogenies: assessing the performance of PhyML 3.0., Syst. Biol. 59 (2010) 307-321. https://doi.org/10.1093/sysbio/syq010.

[71] K. Katoh, K. Misawa, K. Kuma, T. Miyata, MAFFT: a novel method for rapid multiple sequence alignment based on fast Fourier transform, Nucleic Acids Res. 30 (2002) 3059-3066.

[72] D. Posada, K.A. Crandall, MODELTEST: testing the model of DNA substitution., Bioinformatics. 14 (1998) 817-818. https://doi.org/10.1093/bioinformatics/14.9.817.

[73] R. Barter, B. Yu, R package "superheat": A Graphical Tool for Exploring Complex Datasets Using Heatmaps, (2017). https://cran.r-project.org/package=superheat.

[74] S.L. Bräuer, D. Vuono, M.J. Carmichael, C. Pepe-Ranney, A. Strom, E. Rabinowitz, D.H. Buckley, S.H. Zinder, S.L. Brauer, D. Vuono, M.J. Carmichael, C. Pepe-Ranney, A. Strom, E. Rabinowitz, D.H. Buckley, S.H. Zinder, Microbial Sequencing Analyses Suggest the Presence of a Fecal Veneer on Indoor Climbing Wall Holds, Curr. Microbiol. 69 (2014) 681-689. https://doi.org/10.1007/s00284-0140643-3.

[75] P.M. Christy, L.R. Gopinath, D. Divya, Microbial dynamics during anaerobic digestion of cow dung, in: Interanational J. Plant, Anim. Environ. Sci., 2014: pp. 86-94. www.ijpaes.com.

[76] T. Shimoyama, A. Yamazawa, Y. Ueno, K. Watanabe, Phylogenetic analyses of bacterial communities developed in a cassette-electrode microbial fuel cell, Microbes Environ. 24 (2009) 188-192. https://doi.org/10.1264/jsme2.ME09108.

[77] T.-S. Song, H.-Y. Cai, Z.-S. Yan, Z.-W. Zhao, H.-L. Jiang, Various voltage productions by microbial fuel cells with sedimentary inocula taken from different sites in one freshwater lake, Bioresour. Technol. 108 (2012) 68-75. https://doi.org/10.1016/J.BIORTECH.2011.11.136.

[78] R. Snell-Castro, J.-J.J. Godon, J.-P.P. Delgenès, P. Dabert, Characterisation of the microbial diversity in a pig manure storage pit using small subunit rDNA sequence analysis, FEMS Microbiol. Ecol. 52 (2005) 229-242. https://doi.org/10.1016/j.femsec.2004.11.016.

[79] M. Sakamoto, The Family Porphyromonadaceae, in: E. Rosenberg, E.F. DeLong, S. Lory, E. Stackebrandt, F. Thompson (Eds.), Prokaryotes Other Major Lineages Bact. Archaea, Springer Berlin Heidelberg, Berlin, Heidelberg, 2014: pp. 811-824. https://doi.org/10.1007/978-3-642-38954-2_132.

[80] C.L. Sears, D.M. Pardoll, Perspective: alpha-bugs, their microbial partners, and the link to colon cancer., J. Infect. Dis. 203 (2011) 306-11. https://doi.org/10.1093/jinfdis/jiq061. 
[81] G. Hajishengallis, R.P. Darveau, M.A. Curtis, The keystone-pathogen hypothesis, Nat Rev Microbiol. 10 (2012) 717-725. https://doi.org/10.1038/nrmicro2873.

[82] H. Tjalsma, A. Boleij, J.R. Marchesi, B.E. Dutilh, A bacterial driver-passenger model for colorectal cancer: Beyond the usual suspects, Nat. Rev. Microbiol. 10 (2012) 575-582. https://doi.org/10.1038/nrmicro2819.

[83] G.N.A. Senhorinho, V. Nakano, C. Liu, Y. Song, S.M. Finegold, M.J. Avila-Campos, Detection of Porphyromonas gulae from subgingival biofilms of dogs with and without periodontitis, Anaerobe. 17 (2011) 257-258. https://doi.org/10.1016/j.anaerobe.2011.06.002.

[84] R. Nomura, M. Shirai, Y. Kato, M. Murakami, K. Nakano, N. Hirai, T. Mizusawa, S. Naka, Y. Yamasaki, M. Matsumoto-Nakano, T. Ooshima, F. Asai, Diversity of fimbrillin among Porphyromonas gulae clinical isolates from Japanese dogs, J Vet Med Sci. 74 (2012) 885-891.

[85] J.C. Lenzo, N.M. O’Brien-Simpson, R.K. Orth, H.L. Mitchell, S.G. Dashper, E.C. Reynolds, Porphyromonas gulae Has Virulence and Immunological Characteristics Similar to Those of the Human Periodontal Pathogen Porphyromonas gingivalis, Infect Immun. 84 (2016) 2575-2585. https://doi.org/10.1128/iai.01500-15.

[86] M.F. Addis, A. Tanca, S. Uzzau, G. Oikonomou, R.C. Bicalho, P. Moroni, The bovine milk microbiota: Insights and perspectives from -omics studies, Mol. Biosyst. 12 (2016) 2359-2372. https://doi.org/10.1039/c6mb00217j.

[87] C. Catozzi, A. Sanchez Bonastre, O. Francino, C. Lecchi, E. De Carlo, D. Vecchio, A. Martucciello, P. Fraulo, V. Bronzo, A. Cuscó, S. D'Andreano, F. Ceciliani, The microbiota of water buffalo milk during mastitis, PLoS One. 12 (2017) 1-20. https://doi.org/10.1371/journal.pone.0184710.

[88] Y. Wagner, B. Noack, T. Hoffmann, E. Jacobs, P. Christian Lück, Periodontopathogenic bacteria multiply in the environmental amoeba Acanthamoeba castellani, Int. J. Hyg. Environ. Health. 209 (2006) 535539. https://doi.org/10.1016/j.ijheh.2006.05.006.

[89] R.J. Collighan, M.J. Woodward, Spirochaetes and other bacterial species associated with bovine digital dermatitis, FEMS Microbiol. Lett. 156 (1997) 37-41. https://doi.org/10.1016/S0378-1097(97)00399-6.

[90] S.M. Finegold, H. Jousimies-Somer, Recently Described Clinically Important Anaerobic Bacteria: Medical Aspects, Clin. Infect. Dis. 25 (1997) S88-S93. https://doi.org/10.1086/516237.

[91] C.L. Haggerty, P.A. Totten, M. Ferris, D.H. Martin, S. Hoferka, S.G. Astete, R. Ondondo, J. Norori, R.B. Ness, Clinical characteristics of bacterial vaginosis among women testing positive for fastidious bacteria., Sex. Transm. Infect. 85 (2009) 242-248. https://doi.org/10.1136/sti.2008.032821.

[92] M.K. Hudspeth, S. Hunt Gerardo, D.M. Citron, E.J. Goldstein, Growth characteristics and a novel method for identification (the WEE-TAB system) of Porphyromonas species isolated from infected dog and cat bite wounds in humans., J. Clin. Microbiol. 35 (1997) 2450-3. https://doi.org/10.1128/jcm.35.10.24502453.1997.

[93] M. Zeb, H. Tariq, W. Khan, E. Khan, A. Hussain, B. Jehan Farooqi, S. Khan Sherwani, H.T.W.K.E.K.A.H.B.J.F.S.K.S. Mubarak Zeb, An Emerging Trend of Anaerobes: Porphyromonas levii Causing Necrotic Vulvo Vaginitis. A Case Report, Int. J. Basic Med. Sci. Pharm. 4 (2014) 15-18. www.ijbmsp.org (accessed February 26, 2020).

[94] L.R.V. Knudsen, Molecular characterisation of the uterine microbiome of dairy cows suffering from endometritis, metritis, and pyometra, Technical University of Denmark, 2014.

[95] T.F. Moreira, E.J. Facury Filho, A.U. Carvalho, M.L. Strube, M.W. Nielsen, K. Klitgaard, T.K. Jensen, Pathology and bacteria related to digital dermatitis in dairy cattle in all year-round grazing system in Brazil, PLoS One. 13 (2018) 1-15. https://doi.org/10.1371/journal.pone.0193870.

[96] S. Blum, J. Brenner, O. Friedgut, Y. Stram, O. Koren, I. Dagoni, A. Munbaz, D. Elad, Isolation of Porphyromonas levii from vaginal samples from cows in herds negative for bovine necrotic vulvovaginitis, Vet. Rec. 163 (2008) 745-747. https://doi.org/10.1136/vr.163.25.745.

[97] Y. Peng, Y.H. Wang, S.Q. Hang, W.Y. Zhu, Microbial diversity in uterus of healthy and metritic postpartum Holstein dairy cows, Folia Microbiol. (Praha). 58 (2013) 593-600. https://doi.org/10.1007/s12223-013-0238-6.

[98] M. Lev, Apparent requirement for vitamin K of rumen strains of Fusiformis nigrescens [36], Nature. 181 (1958) 203-204. https://doi.org/10.1038/181203a0.

[99] S.E. Dowd, T.R. Callaway, R.D. Wolcott, Y. Sun, T. McKeehan, R.G. Hagevoort, T.S. Edrington, Evaluation of the bacterial diversity in the feces of cattle using $16 \mathrm{~S}$ rDNA bacterial tag-encoded FLX amplicon pyrosequencing (bTEFAP), BMC Microbiol. 8 (2008) 1-8. https://doi.org/10.1186/14712180-8-125.

[100] P.G. Koringa, J.R. Thakkar, R.J. Pandit, A.T. Hinsu, M.J. Parekh, R.K. Shah, S.J. Jakhesara, C.G. Joshi, Metagenomic characterisation of ruminal bacterial diversity in buffaloes from birth to adulthood using 16S rRNA gene amplicon sequencing, Funct. Integr. Genomics. 19 (2019) 237-247. 
https://doi.org/10.1007/s10142-018-0640-x.

[101] S.J. Jeon, F. Cunha, A. Vieira-Neto, R.C. Bicalho, S. Lima, M.L. Bicalho, K.N. Galvão, Blood as a route of transmission of uterine pathogens from the gut to the uterus in cows, Microbiome. 5 (2017) 109. https://doi.org/10.1186/s40168-017-0328-9.

[102] M. Sweeney, J. Watts, E. Portis, M. Lucas, R. Nutsch, D. Meeuwse, D. Bade, V. Oliver, D.W. Morck, D. Shinabarger, S. Poppe, M. Peterson, D. Sweeney, M. Knechtel, G. Zurenko, Identification of Porphyromonas levii isolated from clinical cases of bovine interdigital necrobacillosis by $16 \mathrm{~S}$ rRNA sequencing, Vet. Ther. 10 (2009) E1-10. http://www.ncbi.nlm.nih.gov/pubmed/20425726 (accessed February 27, 2020).

[103] T.M.A. Santos, R. Gilbert, R.C. Bicalho, Metagenomic analysis of the uterine bacterial microbiota in healthy and metritic postpartum dairy cows, J. Dairy Sci. 94 (2011) 291-302. https://doi.org/10.3168/jds.2010-3668.

[104] D.A. Bemis, C.B. Greenacre, M.J. Bryant, R.D. Jones, S.A. Kania, Isolation of a variant Porphyromonas sp. from polymicrobial infections in central bearded dragons (Pogona vitticeps), J. Vet. Diagnostic Investig. 23 (2011) 99-104. https://doi.org/10.1177/104063871102300116.

[105] B. Kim, H. Pai, K.T. Hwang, Y. Lee, Porphyromonas pogonae identification from a soft tissue infection: The first human case, Anaerobe. 42 (2016) 37-39. https://doi.org/10.1016/j.anaerobe.2016.08.002.

[106] P. Schröttner, K. Heidrich, W.W. Rudolph, F. Stölzel, E. Jacobs, F. Gunzer. First report on sepsis caused by Porphyromonas pogonae, Anaerobe. 44 (2017) 96-98. https://doi.org/10.1016/j.anaerobe.2017.02.016.

[107] A. Romero de Oliveira, J.M. Nürmberger, M. Issa, V. Pinto, M.M.K. Bond, J.T. Rabelato, M.B. Meirelles, L. Miglioli, C.S. Abboud, Late ascending aortic prosthesis infection by Porphyromonas pogonae: An unexpected infectious complication, Anaerobe. 56 (2019) 106-108. https://doi.org/10.1016/j.anaerobe.2019.01.006.

[108] T. Yano, K.K. Moe, K. Yamazaki, T. Ooka, T. Hayashi, N. Misawa, Identification of candidate pathogens of papillomatous digital dermatitis in dairy cattle from quantitative $16 \mathrm{~S}$ rRNA clonal analysis, Vet. Microbiol. 143 (2010) 352-362. https://doi.org/10.1016/j.vetmic.2009.12.009.

[109] D. Lu, F. Tiezzi, C. Schillebeeckx, N.P. McNulty, C. Schwab, C. Shull, C. Maltecca, Host contributes to longitudinal diversity of fecal microbiota in swine selected for lean growth, Microbiome. 6 (2018) 1 15. https://doi.org/10.1186/s40168-017-0384-1.

[110] Y. Oishi, K. Watanabe, H. Kumada, E. Ishikawa, N. Hamada, Purification and characterization of a novel secondary fimbrial protein from Porphyromonas gulae, J Oral Microbiol. 4 (2012). https://doi.org/10.3402/jom.v4i0.19076.

[111] C. O’Flynn, O. Deusch, A.E. Darling, J.A. Eisen, C. Wallis, I.J. Davis, S.J. Harris, C. O’Flynn, O. Deusch, A.E. Darling, J.A. Eisen, C. Wallis, I.J. Davis, S.J. Harris, Comparative Genomics of the Genus Porphyromonas Identifies Adaptations for Heme Synthesis within the Prevalent Canine Oral Species Porphyromonas cangingivalis, Genome Biol. Evol. 7 (2015) 3397-3413. https://doi.org/10.1093/gbe/evv220.

[112] S. Arastu-Kapur, M. Nguyen, D. Raha, F. Ermini, U. Haditsch, J. Araujo, I.A.M. De Lannoy, M.I. Ryder, S.S. Dominy, C. Lynch, L.J. Holsinger, Treatment of Porphyromonas gulae infection and downstream pathology in the aged dog by lysine-gingipain inhibitor COR388, Pharmacol. Res. Perspect. 8 (2020) e00562. https://doi.org/10.1002/prp2.562.

[113] H. Inaba, R. Nomura, Y. Kato, H. Takeuchi, A. Amano, F. Asai, K. Nakano, R.J. Lamont, M. MatsumotoNakano, Adhesion and invasion of gingival epithelial cells by Porphyromonas gulae, PLoS One. 14 (2019) e0213309. https://doi.org/10.1371/journal.pone.0213309.

[114] N. Hamada, Y. Takahashi, K. Watanabe, H. Kumada, Y. Oishi, T. Umemoto, Molecular and antigenic similarities of the fimbrial major components between Porphyromonas gulae and P. gingivalis, Vet Microbiol. 128 (2008) 108-117. https://doi.org/10.1016/j.vetmic.2007.09.014.

[115] E. Gaetti-Jardim, M.F. Pereira, E.M.M. Vieira, C.M. Schweitzer, A.C. Okamoto, M.J. Ávila-Campos, Occurrence of periodontal pathogens in ethnic groups from a native Brazilian reservation, Arch. Oral Biol. 60 (2015) 959-965. https://doi.org/10.1016/j.archoralbio.2015.01.002.

[116] N. Noguchi, Y. Noiri, M. Narimatsu, S. Ebisu, Identification and localization of extraradicular biofilmforming bacteria associated with refractory endodontic pathogens, Appl. Environ. Microbiol. 71 (2005) 8738-8743. https://doi.org/10.1128/AEM.71.12.8738-8743.2005.

[117] Y. Yamasaki, R. Nomura, K. Nakano, S. Naka, M. Matsumoto-Nakano, F. Asai, T. Ooshima, Distribution of periodontopathic bacterial species in dogs and their owners, Arch. Oral Biol. 57 (2012) 1183-1188. https://doi.org/10.1016/j.archoralbio.2012.02.015.

[118] F.E. Dewhirst, Canine oral bacteria identified in human skin microbiome libraries, 324 (2012) 36067. ftp://www.homd.org/poster/2012c.pdf. 
[119] H.E. Booij-Vrieling, W.A. van der Reijden, D.J. Houwers, W.E.A.J. de Wit, C.J. Bosch-Tijhof, L.C. Penning, A.J. van Winkelhoff, H.A.W. Hazewinkel, Comparison of periodontal pathogens between cats and their owners, Vet. Microbiol. 144 (2010) 147-152. https://doi.org/10.1016/J.VETMIC.2009.12.046.

[120] S. Yachida, S. Mizutani, H. Shiroma, S. Shiba, T. Nakajima, T. Sakamoto, H. Watanabe, K. Masuda, Y. Nishimoto, M. Kubo, F. Hosoda, H. Rokutan, M. Matsumoto, H. Takamaru, M. Yamada, T. Matsuda, M. Iwasaki, T. Yamaji, T. Yachida, T. Soga, K. Kurokawa, A. Toyoda, Y. Ogura, T. Hayashi, M. Hatakeyama, H. Nakagama, Y. Saito, S. Fukuda, T. Shibata, T. Yamada, Metagenomic and metabolomic analyses reveal distinct stage-specific phenotypes of the gut microbiota in colorectal cancer, Nat. Med. 25 (2019) 968-976. https://doi.org/10.1038/s41591-019-0458-7.

[121] S. Graspeuntner, The cervical microbiome in female infectious infertility: clinical trial and experimental mouse models, University of Lübeck, 2017. https://d-nb.info/1142648095/34 (accessed March 5, 2020).

[122] V. Iebba, F. Guerrieri, V. Di Gregorio, M. Levrero, A. Gagliardi, F. Santangelo, A.P. Sobolev, S. Circi, V. Giannelli, L. Mannina, S. Schippa, M. Merli, Combining amplicon sequencing and metabolomics in cirrhotic patients highlights distinctive microbiota features involved in bacterial translocation, systemic inflammation and hepatic encephalopathy., Sci. Rep. 8 (2018) 8210. https://doi.org/10.1038/s41598018-26509-y.

[123] S. Harakeh, S. Bahijri, G. Ajabnoor, A. Al-Hejin, M.W. Pfaffl, S. Farraj, G. Hegazy, S. Masaudi, S. Barnawi, A. Ahmed, S. Alfadul, E. Azhar, Obesity and microbiota among healthy Saudis with various degrees of obesity, in: 9th Euro Glob. Gastroenterol. Conf., Valencia, Spain, 2016. https://doi.org/10.4172/2161-069X.C1.043.

[124] S. Parida, D. Sharma, The power of small changes: Comprehensive analyses of microbial dysbiosis in breast cancer., Biochim. Biophys. Acta. Rev. Cancer. 1871 (2019) 392-405. https://doi.org/10.1016/j.bbcan.2019.04.001.

[125] D.A. Talan, D.M. Citron, F.M. Abrahamian, G.J. Moran, E.J. Goldstein, Bacteriologic analysis of infected dog and cat bites. Emergency Medicine Animal Bite Infection Study Group., N. Engl. J. Med. 340 (1999) 85-92. https://doi.org/10.1056/NEJM199901143400202.

[126] J. Dhillon, J. Hoopes, T. Epp, Scoping decades of dog evidence: a scoping review of dog bite-related sequelae, Can. J. Public Heal. (2018) 1-12.

[127] M.D.A. Petit, T.J.M. van Steenbergen, L.M.H. Scholte, U. van der Velden, J. de Graaff, Epidemiology and transmission of Porphymmonas gingivalis and Actinobacillus actinomycetemcomitans among children and their family members: A report of 4 surveys, J. Clin. Periodontol. 20 (1993) 641-650. https://doi.org/10.1111/j.1600-051X.1993.tb00709.x.

[128] M. Saarela, B. von Troll-Lindén, H. Torkko, A. -M Stucki, S. Alaluusua, H. Jousimies-Somer, S. Asikainen, Transmission of oral bacterial species between spouses, Oral Microbiol. Immunol. 8 (1993) 349-354. https://doi.org/10.1111/j.1399-302X.1993.tb00610.x.

[129] T.J.M. van Steenbergen, M.D.A. Petit, L.H.M. Scholte, U. van der Velden, J. de Graaff, Transmission of Porphyromonas gingivalis between spouses, J. Clin. Periodontol. 20 (1993) 340-345. https://doi.org/10.1111/j.1600-051X.1993.tb00370.x.

[130] M. Tuite-Mcdonnell, A.L. Griffen, M.L. Moeschberger, R.E. Dalton, P.A. Fuerst, E.J. Leys, Concordance of Porphyromonas gingivalis Colonization in Families Downloaded from, 1997. http://jcm.asm.org/ (accessed March 9, 2020).

[131] H. Asano, K. Ishihara, T. Nakagawa, S. Yamada, K. Okuda. Relationship Between Transmission of Porphyromonas gingivalis and fimA Type in Spouses, J. Periodontol. 74 (2003) 1355-1360. https://doi.org/10.1902/jop.2003.74.9.1355.

[132] M.C. Rijnsburger, S. Delwel, K. Boutaga, T.J.M. Van Steenbergen, P.H.M. Savelkoul, A.J. Van Winkelhoff, Comparison of restriction enzyme analysis and amplified fragment length polymorphism typing of Porphyromonas gingivalis isolated from spouses, Oral Microbiol. Immunol. 22 (2007) 369373. https://doi.org/10.1111/j.1399-302X.2007.00372.x.

[133] M. Belcheva, Transmission of Porphyromonas gingivalis from caregivers to children, J. IMAB - Annu. Proceeding (Scientific Pap. 18, 2 (2012) 157-162. https://doi.org/10.5272/jimab.2012182.157.

[134] X. Feng, L. Zhu, L. Xu, H. Meng, L. Zhang, X. Ren, R. Lu, Y. Tian, D. Shi, X. Wang, Distribution of 8 periodontal microorganisms in family members of Chinese patients with aggressive periodontitis, Arch. Oral Biol. 60 (2015) 400-407. https://doi.org/10.1016/j.archoralbio.2014.11.015.

[135] K. Adhikari, C.S. Saimbi, B.P. Gupta, Estimation of Transmission of Porphyromonas gingivalis from Mother to Child through Saliva., JNMA. J. Nepal Med. Assoc. 56 (2018) 781-786. http://www.ncbi.nlm.nih.gov/pubmed/30387469 (accessed March 9, 2020).

[136] S. Asikainen, C. Chen, S. Alaluusua, J. Slots, Can one acquire periodontal bacteria and periodontitis from a family member? J. Am. Dent. Assoc. 128 (1997) 1263-1271. https://doi.org/10.14219/jada.archive.1997.0403. 